\title{
Intervenção do profissional de Educação Física, gestão intersetorial e territorialidade: o caso do programa $\mathrm{BH}$ Cidadania
}

\author{
Carolina Gontijo Lopes* \\ Hélder Ferreira Isayama**
}

\begin{abstract}
Resumo: Este estudo tem como objetivo analisar a intervenção de profissionais de Educação Física na gestão intersetorial e focalizada em territórios do programa $\mathrm{BH}$ Cidadania/Belo Horizonte. As fontes de informações foram as observações do trabalho cotidiano do profissional, as entrevistas semiestruturadas e as aproximações com os documentos do programa. Concluímos que para atuar com a complexidade desses territórios a intervenção profissional trata as questões de: mobilização da comunidade; abertura a práticas participativas; o trabalho em conjunto, o reconhecimento de saber dos diferentes profissionais e da população.
\end{abstract}

Palavras-chave: Vulnerabilidade social. Políticas públicas. Esportes. Atividades de lazer.

\section{INTRODUÇÃo}

A problemática de pesquisa compreende as percepções do profissional de Educação Física sobre as novas formas de fazer políticas sociais. Tal contexto de atuação historicamente definiuse em meio à precariedade de equipamentos de esporte e lazer, a rotatividade dos trabalhadores, a insegurança na intervenção cotidiana e as orientações clientelistas e funcionalistas. Sem desconsiderar essas questões, ao adotarmos a ênfase nos princípios de intersetorialidade e territorialidade orientando as

\footnotetext{
${ }^{*}$ Curso de Sociologia: Cidades e Culturas Urbanas. Faculdade de Economia. Universidade de Coimbra, Coimbra, Portugal. E-mail: carolminasfef@yahoo.com.br

**Programa de Pós Graduação em Estudos do Lazer. Escola de Educação Física, Fisioterapia e Terapia Ocupacional. Universidade Federal de Minas Gerais, Belo Horizonte, MG, Brasil. E-mail: helderisayama@yahoo.com.br
} 
políticas sociais, defrontamos com algumas especificidades no cotidiano da atuação, tais como: a necessidade do reconhecimento do profissional da Educação Física (FONSECA et al., 2007; MINELLI, 2009; DAMICO, 2013), a inserção da comunidade nas ações (ALMEIDA et al., 2014; TSCHOKE et al., 2011; PERES et al., 2005) e o crescente número de projetos sociais de esporte e lazer (VIANNA; LOVISOLO, 2009).

Um programa que adota esses princípios é o programa $B H$ Cidadania, que busca o enfrentamento da pobreza pela inclusão social das famílias moradoras das áreas de vulnerabilidade em Belo Horizonte (PREFEITURA..., 2004). A escolha deste caso deve-se ao fato do programa articular as políticas sociais de saúde, educação, assistência social, habitação e esportes e lazer, em unidades integradas de intervenção nos territórios (PREFEITURA..., 2004). A Secretaria Municipal Adjunta de Esportes (SMAES) é a instância municipal responsável pelas políticas de esporte e lazer no BH Cidadania. Os analistas técnicos dessa secretaria que atuam no programa são os sujeitos deste estudo. Eles realizam a gestão de políticas de esporte e lazer articulando diretrizes e ações da SMAES com as do BH Cidadania.

Frente ao contexto complexo de exclusões sociais, as gestões governamentais adotam políticas públicas focalizadas e intersetoriais como respostas a esses problemas. As propostas focalizadas em ações afirmativas como cotas, incentivos fiscais e programas especiais incorporam a "[...] discriminação positiva ao atender de forma privilegiada segmentos como os grupos de risco até então excluídos" (FARAH, 2006, p.61). O BH Cidadania pela territorialidade é uma política de ação afirmativa que "consiste em elaborar o planejamento social após a definição das regiões ou áreas urbanas relevantes, que possuem características geográficas determinadas e certa oferta de bens e serviços" (PBH, 2005, p.212). Refere-se à estruturação e delimitação de recortes territoriais através de dados georreferenciais dos indicadores sociais, urbanos e de saúde que estabelecem as áreas de vulnerabilidade focalizadas no munícipio. O vetor espacial é estruturante por estabelecer os

Movimento, Porto Alegre, v. 20, n. 3, p. 895-915, jul./set. de 2014. 
territórios de atuação (BRONZO, 2005). Nesse sentido, abordamos o território como a comunhão de elementos entre espaços e sujeitos com suas características físicas e suas relações sociais (SANTOS, 2008).

Concebemos a intersetorialidade pela perspectiva da visão da complexidade dos sujeitos e dos territórios orientando a intervenção (CAMPOS, 1999) e esta ótica compreende os sujeitos nas diferentes dimensões da vida social, como a saúde, educação, habitação, emprego, renda, cultura, esporte e lazer. Busca-se entender que para a integralidade dos sujeitos essas precisam ocorrer sinergicamente.

No BHCidadania, a inserção da orientação intersetorial decorre dos problemas de fragmentação das políticas sociais; da existência da sobreposição de ações sociais em territórios vulneráveis em que famílias são atendidas por diversos programas com propostas semelhantes; do desperdício de recursos públicos principalmente ao investimento fragmentado; da dificuldade de identificação dos problemas sociais pelo trabalho setorial e do ineficiente atendimento à população residente em áreas de risco que são o público-alvo da sua política pública (MOURÃO, 2007). Diante a dessas questões, a perspectiva intersetorial implementada configura-se pela estratégia de articular serviços no território (BRONZO, 2005).

Nesse contexto, questionamos: como atua o analista técnico de esporte e lazer na gestão intersetorial e focalizada em territórios vulneráveis no $\mathrm{BH}$ Cidadania? Os resultados desse estudo podem fornecer aos profissionais de educação física que atuam com políticas públicas de esporte e lazer compreensões que ajudam na qualificação de sua intervenção, bem como pode contribuir para a avaliação do programa.

\section{Metodologia}

A pesquisa qualitativa combinou dados teóricos com empíricos para analisar a intervenção do profissional de Educação Física pela ênfase na gestão intersetorial e focalizada em

Movimento, Porto Alegre, v. 20, n. 3, p. 895-915, jul./set. de 2014. 
territórios do BH Cidadania. Adotamos filtros para discutir a ação profissional pelo destaque nas orientações dos princípios políticos de intersetorialidade e territorialidade.

Os dados empíricos proveem de observações participantes e entrevistas semiestruturadas. A delimitação da amostra dos entrevistados considerou o quadro de profissionais da SMAES atuante no BH Cidadania, que são 13 analistas técnicos, 27 supervisores técnicos e 70 monitores. A seleção dos analistas técnicos deve-se à condição de funcionários públicos efetivos e à formação em Educação Física, como também considerou sua formação continuada e a possibilidade de análise de profissionais de todos os núcleos do programa no município. É importante frisar que esses sujeitos são os responsáveis pela formulação, implementação, execução e avaliação das políticas de esporte e lazer no BH Cidadania. Entretanto, consideramos que os 13 analistas possuem distintas trajetórias no programa, principalmente pelo tempo de atuação e pelas maneiras e motivos de ingresso.

A imersão começou com as observações participantes das ações rotineiras dos analistas, tais como: reuniões internas no equipamento administrativo da SMAES, entre os setores e representantes da população nos territórios e com as equipe da SMAES nos núcleos do programa. Em seguida, realizamos as 13 entrevistas. Aproximamos, ainda, dos documentos do programa para compreender seus conceitos, propostas, percursos e auxiliar na análise de dados. Todos os dados foram analisados pela técnica de análise de conteúdo (TRIVIÑOS, 1987).

\section{LUgAR do ESPORTE E LAZER NO DESENHO DO $\boldsymbol{B} \boldsymbol{H}$ CIDADANIA}

O programa $B H$ Cidadania é uma ação da Secretaria Municipal de Políticas Sociais (SMPS) da Prefeitura Municipal de Belo Horizonte. Cada núcleo do programa articula os serviços sociais locais no território priorizado. A articulação ocorre nos eixos estratégicos (são eles: direito à saúde, direito à educação,

Movimento, Porto Alegre, v. 20, n. 3, p. 895-915, jul./set. de 2014. 
Intervenção do profissional de Educação Física...

transferência de renda, inclusão produtiva e socialidade) e são orientadas pelos princípios políticos de intersetorialidade, territorialidade, descentralização e participação popular. No período de coletas de dados, totalizavam 27 núcleos com ações específicas do setor de esporte e lazer.

A SMPS através da Câmara Intersetorial de Políticas Sociais (CIPS) deve articular e coordenar as ações políticas e sociais do programa (FARIA, 2009). A CIPS é a unidade administrativa de gestão pensada para integrar os setores sociais no nível central, para tanto cada setor possui seus representantes. Nos núcleos, sob a responsabilidade da assitência social, a articulação das ações deve ocorrer nas reuniões da Comissão Local (CL), como também no Espaço BH Cidadania. A Comissão Local é a instância organizativa proposta pelo programa para articular as ações com a rede de serviços local e regional que deveria ser composta por representantes dos serviços locais e da população.

O Espaço BH Cidadania foi elaborado para agregar os Núcleos de Apoio à Família (NAF), as salas para atividades culturais, o reforço escolar e a inclusão digital, além de espaços para reuniões e capacitações comunitárias e para atividades de planejamento do programa. Aloca também quadras poliesportivas e escolas de educação infantil (UMEI). Destacamos que nem todos os núcleos possuem tal infraestrutura específica para desenvolver as ações do programa.

Já a inserção da SMAES consiste na disponibilização de espaços físicos, equipamentos, atividades de esporte e lazer e equipe de profissionais. Para executar as ações de esporte e lazer, além do Espaço BH Cidadania, utilizam equipamentos específicos: campos de futebol, praças de esporte, Centro de Atendimento Comunitário (CAC), parques e quadras. As ações também ocorrem em escolas públicas, instituições privadas, salões de igrejas e ONGs.

A operacionalização das intervenções nos eixos estratégicos ocorre pela convergência de ação das secretarias municipais e setores agregados da administração municipal (saúde, educação,

Movimento, Porto Alegre, v. 20, n. 3, p. 895-915, jul./set. de 2014. 
cultura, assistência social, abastecimento, direitos da cidadania, esportes) e de organizações não governamentais existentes em cada território (BRONZO, 2005). O eixo socialidade, que é o espaço de intervenção direta das políticas de esporte e lazer, busca enfatizar as relações de convivência e vizinhança por meio de práticas pedagógicas, assistenciais, artistícas, de esporte e lazer, de segurança alimentar e de saúde ${ }^{1}$.

Sobre o lugar da intervenção do analista técnico de esporte e lazer, observamos que este trabalha no espaço administrativo da SMAES, nos Espaços do BH Cidadania e nos espaços concedidos ao programa em cada território. Na secretaria elabora, planeja e avalia as ações junto ao setor de esporte e lazer, já nos territórios, além da gestão das ações junto à equipe executora (supervisores e monitores), o analista participa da Comissão Local e de outras reuniões intersetoriais. Os 13 analistas realizam a gestão dos 27 núcleos do programa, assim, cada um é responsável por dois a quatro núcleos.

A prioridade do atendimento às famílias moradoras das vilas e favelas repercute na maneira de intervir do analista técnico de esporte e lazer. Por um lado, a urbanização desses territórios em aglomerados configura núcleos habitacionais com poucos e, muitas vezes, inadequados espaços e equipamentos para práticas de esporte e lazer. Pelo outro, a associatividade dos atendidos é reduzida devido à fragmentação de vínculos familiares e comunitários desses locais. A complexidade territorial tensiona as possibilidades de respostas pelo trabalho setorial, bem como ocasiona resistências por parte da intervenção profissional. Tal realidade auxiliou na definição das categorias: especificidades territoriais, empoderamento dos sujeitos, estrutura organizativa e cultura operacional para compreender a relação entre a intervenção do profissional de Educação Física e os princípios de intersetorialidade e territorialidade em ações sociais.

1Dados obtidos do site do BH Cidadania. Disponível em<http://portalpbh.pbh.gov.br/pbh/ecp/ comunidade ?evento=portlet\&pldPIc=ecpTaxonomiaMenu Portal\&app= politicassociais\&tax= 8962\&lang=pt_BR\&pg=5567\&taxp=0\&>. Acesso em: $15 \mathrm{dez} .2011$.

Movimento, Porto Alegre, v. 20, n. 3, p. 895-915, jul./set. de 2014. 


\section{DA TERRITORIALIDADE À INTERSETORIALIDADE: POSSIBILIDADES E LIMITES À INTERVENÇÃO PROFISSIONAL}

Confrontado pelas orientações dos princípios de territorialidade e intersetorialidade, o cotidiano de trabalho do analista se depara com possibilidades e limites à intervenção profissional. No âmbito da territorialidade, delimitamos duas questões a serem discutidas, que são: a precariedade das infraestruturas de esporte e lazer e os vínculos sociais reduzidos entre os moradores. Pela intersetorialidade, o debate ocorre na relação entre as estruturas organizativas (como a Comissão Local) e a cultura operacional (como o trabalho em conjunto, o reconhecimento de saberes e a flexibilidade).

As questões apresentadas decorrem da interpretação das percepções dos analistas sobre os princípios no processo de descrição de sua atuação profissional. O primeiro problema narrado pelos sujeitos refere principalmente à relação entre infraestrutura física e formação urbana dos territórios, muito deles são aglomerados de casas que não possuem nem espaço e nem estrutura adequada de serviços da prefeitura, principalmente para as políticas de esporte e lazer. Pelos relatos dos entrevistados constatamos questões relativas às especificidades territoriais, como a precariedade, adaptações e alterações na infraestrutura para executar as ações de lazer no território:

Quando começamos, de maneira geral, os núcleos iniciais tinham uma dificuldade muito grande com relação a equipamento e a estrutura. Eu acredito que para implantar e dentro do recorte territorial, [...], nós fazíamos a busca por espaços ou por adequação de espaços. De lá prá cá, é perceptível que tiveram alterações [...] por que alguns núcleos foram inaugurados e outros núcleos foram remanejados (ENTREVISTADO 3).

Cada território tem uma especificidade, alguns têm espaços físicos adequados para práticas das atividades com quadra, muitas vezes, quadras cobertas, outros já não têm equipamento esportivo próximo. Tem que fazer um deslocamento

Movimento, Porto Alegre, v. 20, n. 3, p. 895-915, jul./set. de 2014. 
da referência que seria o CRAS, o Centro de Referência da Assistência Social, até esse local, outros nem isso. As atividades são desenvolvidas, muitas vezes, em locais não adequados, são feitas atividades adaptadas ali. [...] Não tem mais só o CRAS, hoje a construção do Espaço $B H$ Cidadania que já contempla uma quadra, um salão que possibilita atividades para terceira idade, o esporte como uma parte da política mesmo do $\mathrm{BH}$ (ENTREVISTADO 6).

As questões referentes à precariedade dos equipamentos específicos condizem com a problemática da realidade das políticas de esporte e lazer já apontadas por Marcellino (2006). Com os limites impostos pela urbanização dos territórios percebemos que no percurso do programa cada núcleo foi realizando alterações e adaptações quanto aos equipamentos. A realidade dos núcleos quanto à disponibilidade de equipamento específico para executar as práticas de esporte e lazer na maioria não se apresenta mais com a mesma precariedade do início do programa, muitos já receberam a construção de equipamentos específicos. Entretanto, ainda existe uma diferença grande de um território para outro com relação ao acesso aos serviços públicos e suas estruturas de equipamentos físicos.

Pela aproximação aos núcleos observamos que a maioria dos analistas possui espaços de referência para coordenar as ações na sua região, mesmo que com grandes diferenças entre elas. Alguns analistas possuem salas específicas para planejar, avaliar, reunir com sua equipe e guardar material, enquanto outros realizam estas propostas em locais adaptados, ou compartilham com outros profissionais e parceiros do território. Consideramos, assim, a construção do Espaço $B H$ Cidadania como uma possibilidade de reconhecimento da intervenção do profissional de Educação Física devido à disponibilidade de equipamentos específicos para planejamento e execução das práticas de esporte e lazer junto aos outros setores sociais.

Enquanto as questões de infraestrutura caracterizaram muitos mais limites à intervenção do profissional de Educação Física, a realidade dos vínculos sociais reduzidos estabelece uma relação 
contrária. Desde a ação inicial dos profissionais da SMAES junto aos profissionais do Centro de Referência da Assistência Social (CRAS) para implantar o programa à negociação das atividades de esporte e lazer com a população, observamos a relevância e a necessidade de sua intervenção:

Eu acho que está começando a perceber que o Esporte e o Lazer eles são muito mais que simplesmente um jogar bola, um passar o tempo, que eles têm muito mais a oferecer. Eu acho que é a partir dessa percepção e também da grande aceitação nossa pela comunidade, muitas vezes, nós somos usados até para abrir algumas portas dentro da comunidade. Abriu um núcleo, qual é a primeira política que vai entrar? É o esporte. Por quê? Porque o esporte consegue mobilizar mais a comunidade e atrair mais a atenção do público (ENTREVISTADO 6).

O entrevistado destaca em sua experiência que o esporte consegue mobilizar mais a comunidade e atrair mais a atenção do público. Os sujeitos que pertencem a esses espaços estão inertes a sucessivos processos de exclusão, a ausência dos mais diversos vínculos e baixo associativismo; apresentam receio, desconfiança e insegurança para integrar aos serviços de atendimento local, para tanto o aspecto motivacional das práticas de esporte e lazer que atrai o público são facilitadoras para implantação de serviços sociais durante o período de deflagração da ação governamental.

Os técnicos da SMAES também relatam que a adequação e/ ou inserção das demandas dos sujeitos nos seus planos de trabalho configura práticas participativas ao programa. Para a maioria o ouvir/consultar os sujeitos na sua atuação profissional compreende uma forma de participação popular. Stigger (2003) considera que a capacidade de escuta do profissional na perspectiva da política de esporte e lazer potencializa a participação popular quando possibilita a apropriação, pela população, do poder de decisão. Os relatos abaixo aproximam dessa identificação:

Quando deslocamos o serviço para as comunidades estamos mais abertos a escuta, a comunidade ela fala, ela tem movimentos, ela

Movimento, Porto Alegre, v. 20, n. 3, p. 895-915, jul./set. de 2014. 
tem gosto, ela tem sentimentos diferentes, cada território que você passa tem um querer diferente (ENTREVISTADO 5).

Você trabalha muito essa questão de ouvir, de ouvir melhor a população, [...] você não está sozinho (ENTREVISTADO 8).

A proposta de ouvir mais a comunidade no planejamento específico das ações [...]. Essa ideia existe atendendo as crianças e ao ouvi-las, ficam mais susceptíveis a manifestar os interesses. Mesmo acontece com adolescentes, ou adultos, ou idosos, isso tem uma consequência que é o seguinte, você não chega com o planejamento pronto, $[\ldots]$, e implementa na comunidade por que aquela proposta talvez não atenda aquela comunidade ou ela no mínimo terá alguns ajustes para atender melhor (ENTREVISTADO 11).

Ao relacionar esses olhares com a possibilidade de alcançar, ampliar ou limitar os processos de empoderamento dos sujeitos que corresponde à ampliação da autonomia pessoal e coletiva, identificamos ações das políticas de esporte e lazer como possibilidade de fortalecimento da estrutura social e da formação de vínculos territoriais. Consideramos esta forma de participação como uma possibilidade de ampliar as dimensões participativas no programa e fomentar o empoderamento dos sujeitos pelo seu "protagonismo no tecido social" (VASCONCELOS, 2003, p. 43).

A ênfase no papel dos técnicos em ouvir os sujeitos para construir as ações locais participativas pode representar seu lugar dominante nos espaços decisórios e na elaboração das políticas. Este olhar é necessário para fomentar a articulação de práticas participativas, entretanto, requer o reconhecimento do saber popular junto ao saber técnico na definição das escolhas. Para atuar nas políticas de esporte e lazer, Stigger (2003, p. 117) sugere o profissional educador:

Dessa forma, o exercício da escuta não se resume a responder às demandas da população (o que é possível acontecer em políticas paternalistas

Movimento, Porto Alegre, v. 20, n. 3, p. 895-915, jul./set. de 2014. 
e assistencialistas, realizadas para a população numa lógica semelhante à do mercado), mas, sim, constitui-se numa política realizada com a participação da população, que se estabelece na democratização do poder decisório, o principal eixo político de uma política social participativa.

Para o autor, isto pode significar mais do que a oferta de serviços devido às condições criadas para elaboração de um projeto coletivo. Planejar as políticas territoriais buscando dialogar com as demandas da comunidade representa, assim, contradições à participação popular. Por um lado, pode fortalecê-la se nesse processo de aprendizagem fomentem aos sujeitos envolvidos autonomia, poder de decisão e a formação de vínculos sociais e territoriais. Por outro lado, podem ocorrer práticas antiparticipativas de cunho clientelista e paternalista. Estas, segundo Stigger (2003), podem ocasionar a personificação de representantes da comunidade ou serviços públicos, que ao tratar as demandas da comunidade estabelecem relações de dependência.

No programa a incorporação das demandas da comunidade e da família foi planejada para ocorrer pela inserção de seus representantes na estrutura da Comissão Local. Entretanto, observamos pouco envolvimento da população nestes espaços, nesse sentido, Avritzer (2007) considera que não basta deliberar uma estrutura participativa para efetivar a participação. A baixa mobilização e associatividade nos territórios do BH Cidadania podem ser os fatores que justificam a reduzida participação na Comissão Local. As formas de participação da população no $B H$ Cidadania retratam o problema que Lipsky (1996) caracterizou entre política planejada e política real.

Se a Comissão Local não corresponde à política planejada pela reduzida participação da população, identificamos outra realidade no âmbito da intersetorialidade pelo envolvimento de diferentes representantes dos serviços locais nessa comissão. Pela aproximação com algumas reuniões de CL, concebemos maiores

Movimento, Porto Alegre, v. 20, n. 3, p. 895-915, jul./set. de 2014. 
aproximações com a proposta intersetorial planejada, como na reunião de avaliação do $B H$ em Férias a seguir:

Seguindo, começaram (psicólogo, arte educador da fundação de cultura, técnico do centro de saúde, analista e supervisor técnico da SMAES, representantes da escola integrada, assistente social coordenadora do Espaço BH Cidadania, técnica do tribunal de justiça, representantes de ONGs e UMEI), a avaliar o BH em Férias do mês de julho de 2011. Buscaram falar do evento no geral e nas especificidades de cada temática. Anunciaram que foi gratificante a partição do CRAS e da comunidade no evento. E falaram que a comunidade gostou. Ressaltaram a pouca participação da Cultura, cujos funcionários estavam de férias, que gerou a pouca inserção nas atividades da cultura. Concluíram que o $B H$ em Férias promove maior aproximação entre o CRAS e o $\mathrm{BH}$ Cidadania principalmente pela prática de lazer, como os passeios (Diário de campo, Belo Horizonte, 25/08/ 2011).

Tanto pela presença de técnicos diversos quanto pelo debate avaliativo entre os representantes dos setores durante a reunião da CL, mesmo que na ausência de integrantes da comunidade, identificamos o trabalho em conjunto sendo desenvolvido. É importante destacar também o papel do $\mathrm{BH}$ em férias na ação intersetorial, pois este projeto de lazer desenvolvido pelo programa, que acontece em quase todos os núcleos, tem o envolvimento de todos os setores das políticas sociais no seu processo de planejamento, de execução e de avaliação.

Os técnicos da SMAES, além de articular ações com os outros setores das secretarias de políticas sociais na CL, também atuam com os parceiros do programa no território do $\mathrm{BH}$ Cidadania. Mediante as demandas locais implementam ações específicas em cada núcleo atendido, apresentando uma diversidade na atuação

Movimento, Porto Alegre, v. 20, n. 3, p. 895-915, jul./set. de 2014. 
desses funcionários, como podemos ver nos relatos que mostram a articulação intersetorial para tratar questões transversais como o lixo e a juventude:

Tem a reunião de lixo que já reúne dois bairros próximos, ela também é mensal.[...]. Existem essas interlocuções, essas conversas intersetoriais (ENTREVISTADO 1).

Têm programas que as reuniões são intersetoriais, o ProJovem para nós, por exemplo, reunimos todo mês para discutir esse programa especificamente com os parceiros envolvidos (ENTREVISTADO 5).

Os territórios que desenvolvem a articulação de temas transversais agregam avanços à perspectiva intersetorial na visão da complexidade dos sujeitos (CAMPOS, 1999). Para realizar o trabalho integrado nos territórios, a cultura operacional deve adequar suas formas de fazer políticas públicas setorializadas. O cotidiano do trabalho intersetorial enfrenta os determinantes da cultura das instituições e das profissões que englobam as relações de poder e a competição desigual de cunho ideológico político e sociotécnico para realizar o trabalho em conjunto entre os setores. Assim, começo pelas narrativas dos analistas da SMAES sobre a cultura operacional que dispõe de maneira consensual do entendimento da intersetorialidade como o trabalho em conjunto entre diferentes técnicos no território:

Intersetorialidade é o trabalhar junto, um estar envolvido com o outro. Um conhecer o trabalho do outro, é um encaminhar para o outro. [...] é o conhecer o outro, de saber as limitações do outro, mas de estar dialogando com esse outro colega o tempo inteiro (ENTREVISTADO 5).

A intersetorialidade é trabalhar com todas as políticas mais integradas, mais articuladas. Você não trabalha mais sozinho, vai organizar determinada atividade e conta com seus parceiros. Depois que este princípio está

Movimento, Porto Alegre, v. 20, n. 3, p. 895-915, jul./set. de 2014. 
entendido e efetivado é muito mais fácil para você trabalhar (ENTREVISTADO 8).

O grande desafio é trabalhar junto, você vê algum problema. Qual é o princípio? É que o problema social hoje não é um problema que vamos resolver só com escola, ou só com a saúde, ou só com a assistência, ou só com os campinhos de futebol ou só com lazer. [...] A partir dessa lógica a atuação chega junto do cidadão, da família no caso, com todas as políticas associadas e trabalhando juntas (ENTREVISTADO 12).

A maneira de abordar o problema pelo viés intersetorial, para os entrevistados acima, compreende o trabalhar junto com os diferentes setores e profissionais. Entendemos as diferenças entre o integrar a ação desde a delimitação de um problema de forma coletiva e atuar em todo o seu processo em conjunto e o dar apoio às ações de cada setor e estabelecer parcerias na ação intersetorial. Concordamos com Gomà e Brugué (1994) que a intersetorialidade envolve o reconhecimento dos outros setores, dos outros profissionais, da população atendida e do contexto territorial. Sobre as formas de reconhecimento, os entrevistados levantam problemas específicos das políticas de lazer na ação intersetorial e possibilidades à sua intervenção no $\mathrm{BH}$ Cidadania:

As políticas de esportes, hoje eu vejo, infelizmente, não assim todos, mas ainda tem aquela perspectiva de espetáculo, de mobilizar, [...] para muito mais como pano de fundo das coisas e não como um direito [...]. A maioria ainda enxerga dessa forma das espetacularização e de mobilização de massas, é para começar as atividades de determinado CRAS, vamos fazer uma rua de lazer, para chamar o povo e chamar atenção. Por que o que chama atenção é uma rua de lazer. Fica aquela atividade de lazer por ela mesma, sem sentido totalmente (ENTREVISTADO 2).

Para você desenvolver ações intersetoriais implica você reconhecer que o saber que você possui na sua área é complementar, não é superior a nenhum outro conhecimento. E é complicado

Movimento, Porto Alegre, v. 20, n. 3, p. 895-915, jul./set. de 2014. 
por que no início você tinha um entendimento que levava a certa hierarquização desses saberes, ou seja, outras secretarias temáticas viam a ação dela como mais importante que as outras. (...) Hoje eu acho que é mais tranquilo, com o tempo você vai construindo, mas no início era muito difícil efetivar esses princípios na prática por que demanda você mudar as posturas dos profissionais e é complicado. (...) A questão mesmo de você dispor mesmo de vaidades profissionais de campo de conhecimento (ENTREVISTADO 8).

A atuação do esporte dentro do BH Cidadania é reconhecida pelos outros parceiros, pelas outras secretarias. Eu percebo que as pessoas consideram que seja uma política e que não veem aquilo ali como oferta de atividades, vai embora, pronto e acabou. Sabe da importância da prática, dos benefícios e dos resultados, sabe o que representa aquilo para comunidade, sabe que aquilo representa melhoria da qualidade de vida daquelas pessoas (ENTREVISTADO 10).

O reconhecimento profissional pode determinar a atuação intersetorial entre os profissionais envolvidos. Analisando as falas dos entrevistados sobre o reconhecimento no $\mathrm{BH}$ Cidadania, percebemos que o consideram como uma dificuldade pelo enfrentamento das visões das políticas de esporte e lazer, associadas ao caráter de espetáculo, mobilização e acessório, além da valorização dessas políticas e de suas práticas e a hierarquia de valores, saberes e setores sociais. Envolve ainda o reconhecimento do profissional que intervém nas políticas de esporte e lazer, que na sua trajetória no programa tem seu trabalho subjugado pelos outros. Quando seus atores compreendem a multiplicidade de conhecimento e interesses das profissões, de regras e valores das instituições setoriais e das condições territoriais da comunidade atendida, o jogo político na ação intersetorial possibilita o reconhecimento das diferentes dimensões desse processo.

Entretanto, os entrevistados relatam que a atuação dos analistas da SMAES é responsável pelo reconhecimento atual do

Movimento, Porto Alegre, v. 20, n. 3, p. 895-915, jul./set. de 2014. 
seu trabalho na estratégia do BH Cidadania. Concordamos que o atual reconhecimento se deve pelo comprometimento da atuação do analista nas ações intersetoriais, mas consideramos também os seguintes fatores: a qualificação desses profissionais; a pouca rotatividade desses servidores públicos; a permanência em alguns casos na mesma região e núcleos; e os incentivos do governo para sua qualificação profissional. Os incentivos para formação compreendem desde investimento financeiro do governo até capacitações internas, como exemplos: "a pós graduação que estou fazendo é paga pela prefeitura" (ENTREVISTADO 4), "um grande momento de capacitação que teve a coordenação da professora Leila Mirtes" (ENTREVISTADO 8) e "a cada especialização que você tem, você recebe 5\% a mais, como exemplo" (ENTREVISTADO 9).

Entretanto, algumas narrativas compreendem visões que fragmentam as maneiras de fazer política pela estratégia do $B H$ Cidadania. Esta corresponde, em alguns núcleos, à diluição da comunicação entre os setores, à dificuldade em compartilhar informações, espaços e ações e ainda à determinação dos saberes e valores das profissões dominantes sobre os outros serviços. Essas dificuldades podem representar formas de resistência dos diferentes atores políticos ao trabalho intersetorial, como os relatos mostram:

As escolas, elas por si, elas se bastam, elas têm um professor de Educação Física, ela têm quadra, elas têm tudo, entramos com um serviço que ficava muito à mercê do perfil do diretor da escola, do perfil do gerente do posto de saúde, naquilo que ele acreditava, (...) se ele não precisava muito, ele criava aquela barreira, por que não abraça essa nossa entrada na escola e no posto de saúde (ENTREVISTADO 1).

Outra questão são essas atividades apenas uma vez por semana. Assim, a prática da atividade física mesmo que seja com o princípio principal da socialização, eu não acho que ela deveria ser oferecida uma vez por semana. (ENTREVISTADO 10).

Movimento, Porto Alegre, v. 20, n. 3, p. 895-915, jul./set. de 2014. 
Eu não vejo esse trabalho de intersetorialidade funcionando tão bem como vejo em outras regionais. Eu vejo certa, não sei se é pelo fato de ter trocado tantas vezes os analistas deste núcleo, isso pode ser um fator de dificuldade, mas eu não vejo a Esportes como um evento de rua de lazer que nós emprestamos os brinquedos (ENTREVISTADO 13).

A visão fragmentada corresponde às restrições para entender o propósito do programa frente ao conhecimento técnico que não compreende o processo da unidade integral de intervenção intersetorial. Entendemos e concordamos com a preocupação pela frequência dos atendidos nas práticas de esporte e lazer levantadas pelos Entrevistados 10 e 13, mas se realmente os sujeitos são atendidos integralmente, os vínculos decorrentes da socialização não correspondem apenas à ação da equipe de esporte e lazer, ele vêm complementar esse processo junto à atuação dos outros profissionais. As ações das políticas de esporte e lazer no território devem ocasionar a interação entre aspectos técnicos e políticos de modo a minimizar as sobreposições de um sobre o outro, podendo, assim, viabilizar maior comprometimento do profissional.

As compreensões dos analistas sobre a intersetorialidade representam na cultura operacional dos profissionais que intervêm no $\mathrm{BH}$ Cidadania a maneira de fazer política em que os atores políticos devem atuar conjuntamente. Para tanto, as formas de trabalhar junto a outros setores sociais variam em meio às questões de: reconhecimento técnico, visão multidimensional ou técnica, enfrentamento da cultura institucional e profissional, compartilhamento de informações, espaços, sujeitos atendidos e problemas e formas de resistência. Para tanto, a flexibilidade na intervenção cotidiana é necessária para aderirem aos processos de aprendizagens decorrentes dessa experiência prática. Os novos conhecimentos vindos da ação intersetorial e focalizada em território decorrem das experiências práticas locais, pelas trocas entre setores, pelo diálogo entre os profissionais e a comunidade no território.

Movimento, Porto Alegre, v. 20, n. 3, p. 895-915, jul./set. de 2014. 


\section{Considerações finaIS}

Mesmo com as limitações e críticas, o percurso do $B H$ Cidadania na gestão das políticas sociais condiz de maneira coerente com seu objetivo de focalização nas famílias dos territórios de vulnerabilidade. Para tanto, adota a forma de gestão que aproxima os serviços públicos da população nos territórios atendidos e implementa estruturas organizativas para possibilitar as ações intersetoriais e a participação popular. Esses caminhos são regados de incertezas que decorrem do problema de enfrentamento da pobreza, bem como de conflitos de interesses entre governo e técnicos, técnicos diferentes e técnicos e população.

No BH Cidadania, observamos que o caráter motivacional das políticas de esporte e lazer é fundamental para o processo de sensibilização comunitária. O profissional educador na intervenção com práticas de esporte e lazer é essencial para o fortalecimento do tecido social nos territórios de vulnerabilidade. Enquanto, a articulação intersetorial possui dificuldade de envolver os diferentes representantes locais, sejam técnicos da saúde ou moradores, em uma agenda integrada. O caso do Projeto $\mathrm{BH}$ em férias é uma possibilidade processual para solucionar este problema.

Tais processos envolvem o reconhecimento ou não do profissional de Educação Física. O enfretamento da cultura das instituições e das profissões para definir o reconhecimento do campo de atuação das políticas de esporte e lazer é primordial também para o reconhecimento do profissional de Educação Física. Os dois processos, sensibilização comunitária e o projeto $\mathrm{BH}$ em férias, são exemplos de momentos que os técnicos da SMAES rompem com essas construções históricas. 


Agency of Physical Education professionals, intersectoral
management and territoriality: the $\mathbf{B H}$ Cidadania program
Abstract: This study's purpose is to analyze interventions of
physical education professionals in intersectoral management and
focused on territories of the program BH Cidadania/Belo Horizonte.
Information sources were observations of professional's day-
to-day work, semi-structured interviews and approachments to
the program's documents. We conclude that in order to act with
theses territories' complexity, professional's intervention treats
the questions of: mobilizing the community; openness towards
participative practices; group work; acknowledgment of different
professional's or the population' knowledge.
Keywords: Social vulnerability. Public policies. Leisure activities.
Sports

Gestión intersectorial, política pública de deporte y ocio y actividades profesionales: el caso del programa $\mathrm{BH}$ Cidadania Resumen: Este estudio tiene como objetivo analizar los avances y limitaciones de la gestión de políticas de deporte y ocio en la articulación intersectorial y en el foco territorial del Programa BH Cidadania/Belo Horizonte, con referencia a la intervención de profesionales de educación física. La actuación de éstos profesionales consiste principalmente en: flexibilidad para trabajar juntos y reconocimiento del conocimiento de los distintos profesionales y de la población.

Palabras Clave: políticas públicas; vulnerabilidad social; actividades recreativas; deportes.

\section{REFERÊNCIAS}

ALMEIDA, Dulce Figeira; WIGGERS; Ingrid Dittrich; NERI, Ana Amélia. Trabalhadores do lazer do Programa Esporte e Lazer da Cidade: uma aproximação à definição do perfil. Movimento, Porto Alegre, v.20, n.1, p.215-238, jan./mar. 2014.

AVRITZER, Leonardo (Org). A participação social no Nordeste. Belo Horizonte: UFMG, 2007.

BRONZO, Carla Bronzo. Programas de proteção social e superação da pobreza: concepções e estratégias de intervenção. 2005. 334 f. Tese (Doutorado) - Faculdade de Filosofia e Ciências Humanas, Universidade Federal de Minas Gerais, Belo Horizonte, 2005.

CAMPOS, Gastão W. S. Equipes de referência e apoio especializado matricial: um

Movimento, Porto Alegre, v. 20, n. 3, p. 895-915, jul./set. de 2014. 
ensaio sobre a reorganização do trabalho em saúde. Ciência \& Saúde Coletiva, Rio de Janeiro, v.4, n.2, p. 393-403, 1999.

DAMICO, José. Gestão da vida a partir do esporte e lazer em Grigny Centre França. Movimento, Porto Alegre, v.1, n.19, p.11-31, jan./mar. 2013.

FARAH, Marta Ferreira Santos. Inovação e governo local no Brasil contemporâneo. In: JACOBI, P.; PINHO, J. A. Inovação no campo da gestão pública local: novos desafios, novos patamares. Rio de Janeiro: FGV. 2006. p. 41-76.

FARIA, Carlos Aurélio Pimenta. O trabalho intersetorial no Programa $\mathbf{B H}$ Cidadania. Belo Horizonte: PMBH, 2009.

FONSECA, Rubiane Giovani; SORIANO, Jeane Barcelos Soriano; NAKAMURA, Silvia Cristina. O conhecimento do profissional de Educação Física e sua relação com o ambiente de trabalho durante a intervenção profissional. Movimento, Porto Alegre, , v.3, n.13, p.1.51-177, set./dez. 2007.

GOMÀ, Ricardo; BRUGUÉ, Quim. Nuevos modelos de géstion y organización pública. Autonomies, Barcelona, n.18, p. 207-229, jul. 1994.

LIPSKY, Michael. Los empleados de base em La eleboración de políticas públicas. In: BRUGÉ, Q.; SUBIRATS, J. Lecturas de gestión pública. Madrid: MAP, 1996. p. 281- 297.

MARCELLINO, Nelson Carvalho. Políticas públicas setoriais de lazer: o papel das prefeituras. Campinas: Autores Associados, 1996.

MINELLI, Daniela Schwabe; SORIANO, Jeane Barcelos; FÁVARO, Paula Evelise. O profissional de Educação Física e a intervenção em equipes multiprofissionais. Movimento, Porto Alegre. v.4, n.15, p.35-62, out./dez. 2009.

MOURÃO, Marcelo. BH Cidadania: avanços e desafios. Revista Pensar BH/ Política Social, Belo Horizonte, n. 17, p. 6-8, mar./maio 2007.

PERES, Fabio de Faria et al. Lazer, esporte e cultura na agenda local: a experiência de promoção da saúde em Manguinhos. Ciência \&Saúde Coletiva, Rio de Janeiro, v.10. n.3, p.757-769, 2005.

PREFEITURA MUNICIPAL DE BELO HORIZONTE. Documento do Programa BH Cidadania. Estudo de identificação e avaliação dos projetos - piloto do $\mathrm{BH}$ Cidadania, 2004. Belo Horizonte: PMBH, 2004.

SANTOS, Milton. Técnica, espaço, tempo: globalização e meio técnico-científicoinformacional. São Paulo: Hucitec, 2008.

STIGGER, Marco Paulo Políticas Públicas em Esportes e Lazer: considerações sobre o profissional educador. In: MARCELLINO, Nelson C. (Org.). Formação e Desenvolvimento de Pessoal em Lazer e Esporte. Campinas: Papirus, 2003. p. 101-120.

TSCHOKE, Aline et al. As experiências no âmbito do lazer e o princípio da inércia:

Movimento, Porto Alegre, v. 20, n. 3, p. 895-915, jul./set. de 2014. 
Intervenção do profissional de Educação Física...

Uma analogia para pensar sobre os fatores que influenciam a apropriação dos espaços públicos. Movimento, Porto Alegre, v.1, n.17, p.117-136, jan/mar. 2011.

TRIVIÑOS, Augusto Nivaldo Silva. Introdução à pesquisa em ciências sociais: a pesquisa qualitativa em educação. São Paulo: Atlas, 1987.

VASCONCELOS, Eduardo Mourão. O poder que brota da dor e da opressão: empowerment, sua história, teorias e estratégias. São Paulo: Paulus, 2003.

VIANNA, José Antonio; LOVISOLO, Hugo Rodolfo. Projetos de inclusão social através do esporte: notas sobre a avaliação. Movimento, Porto Alegre, n.15, v.3, p.145-162, jul./set. 2009.

Endereço para correspondência:

Carolina Gontijo Lopes

Hélder Ferreira Isayama

Oricolé - EEFFTO - UFMG

Av. Antonio Carlos 6627 Pampulha

Belo Horizonte - MG - 31270-901

Recebido em: 08.07.2013

Aprovado em: 20.03.2014

Movimento, Porto Alegre, v. 20, n. 3, p. 895-915, jul./set. de 2014. 